\title{
The Peculiarities of Health-Related Quality of Life in Recreational and Competitive Athletes
}

\author{
Ilona Tilindienè, Lina Petkūnè, Dovydas Ivanauskas \\ Lithuanian Sports University, Kaunas, Lithuania
}

\begin{abstract}
Background. The scientific literature focuses on the evaluation of quality of life (QL) and health-related quality of life (HRQL) among recreational and competitive athletes. Research suggests that the QL and HRQL levels of competitive athletes can be negatively affected in that they spend most of their lives in training, preparing for and recovering from competitions and tournaments; however, they neither learn most of the essential life skills (Ohlert \& Ott, 2017), nor allot time to their leisure activities and recreation. There are also contradictory studies indicating that competitive athletes evaluate HRQL better than recreational ones do (Lorcan \& Allen, 2018; Pacesova, Smela, \& Antala, 2019). However, little is known about the impact of how different levels of sports activities affect HRQL in this pandemic period.

Methods. HRQL was evaluated applying the SF-36 questionnaire (Short Form 36 Medical Outcomes Study questionnaire). The questionnaire was adapted in Lithuania (Staniūtè, 2007).

Results. Statistically significant differences were found in the evaluation of quality of life in the following areas: social function, pain, and activity limitation due to emotional disorders. It was found that competitive athletes limited their activities more than recreational athletes due to emotional difficulties $(U=1165, p=.05)$ and experienced more pain $(U=1036, p=.01)$. It was also found that recreational athletes valued their social relations more favourably than competitive ones $(U=1066, p=.02)$. Statistically significant differences were found in the evaluation of HRQL by gender. Men value their social relations better $(U=992.5, p=.00)$ and have fewer activity limitations due to emotional difficulties $(U=1063, p=.02)$ than women. The HRQL evaluation by gender and sport level shows that in recreational sports men evaluated their social relationships better than women and had fewer activity limitations due to emotional difficulties than women. Analysis of HRQL of competitive athletes showed no statistically significant relationship between women and men groups.

Conclusion. In conclusion, it can be stated that athletes best valued areas of physical activity and social relations. The findings show that competitive athletes more than recreational ones limited their activities due to emotional difficulties, and experienced more pain. Meanwhile, recreational athletes rated their social relations more favourably than competitive athletes. It was found that male athletes valued their social relations and emotional state better than female athletes. Men also had fewer activity limitations due to emotional difficulties than women.
\end{abstract}

Keywords: quality of life, young adults, recreational athletes, competitive athletes.

\section{INTRODUCTION}

$\mathrm{N}$ owadays, people pay a lot of attention to their quality of life, and especially healthrelated quality of life. WHO (2012) defines Quality of life (QL) as an individual's perception of their position in life in the context of the culture and value systems in which they live and in relation to their goals, expectations, standards and concerns (https://www.who.int/tools/whoqol). QL levels are reported to depend on physical health, social, interpersonal relationships and social integration,

Copyright $(2021$ Ilona Tilindienė, Lina Petkūnė, Dovydas Ivanauskas. Published by Lithuanian Sports University.

This is an Open Access article distributed under the terms of the Creative Commons Attribution 4.0 International License, which permits unrestricted use, distribution, and reproduction in any medium, provided the original author and source are credited. 
material well-being (Kalman \& Hantiu, 2017), and fulfilment of human needs (Brazier, Papaioannou, Connell, \& Mukuria, 2014). Emphasis is also placed on psychological health, i.e. good relationships with others, self-confidence, personal and social values, and good individual qualities are strongly associated with a happy life and high QL (Demirci \& Ekşi, 2018; Snedden et al., 2019). One aspect of QL is health-related quality of life (HRQL), which largely depends on physical activity. It is stated that individuals who have been physically active since their childhood have better healthy lifestyle skills and physical and psychological advantages than do physically inactive individuals (Cakir \& Kalkavan, 2020; Ekblom-Bak, Ekblom, Andersson, Wallin, \& Ekblom, 2018). Physical activity and sport are cited as measures to improve people's mental health levels, especially in the prevention of depression and anxiety (de Oliveira, Edila, Rodrigues, Fett, \& Piva, 2019; Päivärinne, Kautiainen, Heinonen, \& Kiviranta, 2018; Snedden et al., 2019). Studies have shown that people who are overweight and not physically active rated their HRQL worse than those who spend their free time being mobile and exercising actively (Koolhaas et al., 2018).

The scientific literature focuses on the evaluation of QL and HRQL among recreational and competitive athletes. Competitive athletes' lifestyles are subordinated to sport, which becomes a way of their life (Stambulova, 1994), and significantly affect their QL from different perspectives (Nemček, 2020). Competitive athletes have 3 to 12 workouts per week depending on the sport and the macrocycle (Bompa \& Haff, 2018). Research suggests that the QL and HRQL levels of competitive athletes can be negatively affected in that they spend most of their lives in training, preparing for and recovering from competitions and tournaments, and consequently they neither learn most of the essential life skills (Ohlert \& Ott, 2017), nor allot time to their leisure activities and recreation. The lack of academic education and early sports career termination are also observed (Filbay et al., 2019) as well as new job search problems (Babic, Bjelic, \& Bosnar, 2019). It is also known that high-performance sport (elite and competitive) can be very dangerous (Filbay et al., 2019), cause serious physical injuries (Goraczko et al., 2020) and consequent psychological traumas: stress, depression, anxiety and eating disorders, and so further career development can be prevented (Gulliver, Griffiths, Mackinnon, Batterham, \&
Stanimirovic, 2016; Schinke, Stambulova, Gangyan, \& Moore, 2017; Petterson \& Olson, 2017). However, there are also contradictory studies indicating that competitive athletes evaluate QL and HRQL better than recreational ones. This may depend on the fact that competitive athletes face factors in their careers that raise the level of QL and HRQL: leadership, communication and collaboration, effective time planning, problem management, making important decisions (Lorcan \& Allen, 2018; Pacesova, Smela, \& Antala, 2019), coaching assistance, professional health care and qualified psychological assistance, as well as a balanced diet (Correia et al., 2017).

Researchers analysing different groups of HRQL find statistically significant gender differences concerning HRQL in male and female. It was found that female athletes expressed the greatest dissatisfaction with their psychological health (Nemček, 2020). It was determined that women reported higher stress intensity for coachrelated sources of acute stress and used approachbehavioural and avoidance-cognitive coping styles more often than their male counterparts (Anshel, Sutarso, \& Jubenville, 2009). In addition, women are significantly more likely to develop depression or anxiety disorders than men, and this leads to psychosocial events such as rolestress, victimization, sex-specific socialization, internalization coping style, and disadvantaged social status (Zagni, Simoni, \& Colombo, 2016) as well as high emotional sensitivity and vulnerability (Batz \& Tay, 2018), even sex differences in the brain determining the expression of male- or female-typical behaviours (Beery \& Zucker, 2011). Analysing the dimension of social relations of HRQL in male and female athletes, the research is controversial. Unver et al. (2015) found that women's social scores were lower than those of men; later Carlquist et al. (2017) found that women's evaluations in the social domain were higher than men's, and recent studies have not found any differences in the field of social relations among male and female athletes (Nemček, 2020).

Research suggests that physical activity/ inactivity can affect one's health-related quality of life. However, little is known about how different levels of sports activities affect HRQL. It is especially important to know these peculiarities in the current pandemic period when physical activity is limited.

The aim of study was to determine differences in health-related quality of life among competitive and recreational male and female athletes. 


\section{METHODS}

Organization of the study. This study was conducted in 2020. The questionnaire was sent via email to the groups of students of Lithuanian Sports University and submitted to the athlete group on the social network Facebook. The preamble of the questionnaire stated the purpose of the study, and participants were informed that they could suspend their participation in the study at any time. In accordance with the principles of anonymity and confidentiality, subjects were not asked to provide personal data (name, surname, date of birth, ID, etc.) and it was explained to them that the survey data would only be used as summary statistics.

Participants. The sample was 109 participants (56 females and 53 males) with a mean age of $25.2 \pm 2.4$. Study participants were divided into competitive $(n=44)$ and recreational $(n=65)$ athletes. Recreational and competitive athletes were divided by gender - recreational: women -30 , men - 35; competitive: women -26 , men -18 . We considered recreational athletes to be respondents who did sports only for their own pleasure and/ or health, and competitive athletes as those who went in for sports 4-6 days a week, participating in competitions and seeking sporting achievement.

Research methods. The SF-36 questionnaire, widely used worldwide, was used to determine the health-related quality of life in athletes (Short Form 36 Medical Outcomes Study questionnaire). The questionnaire was adapted in Lithuania (Staniūte, 2007). Using this questionnaire, the respondents' well-being over the last four weeks was evaluated. The questionnaire consisted of 36 questions that reflected eight areas of life: physical activity ("These questions are about the activities you do on a daily basis. Does your health limit these activities? If so, how much?"); restriction of activities due to physical ailments ("Have you had any of the following problems related to work or other regular daily activities due to physical health In the last 4 weeks?"); and emotional difficulties ("Have you had any of the following problems with your work or other regular daily activities due to any emotional disturbances (such as depression or anxiety) in the last 4 weeks?"); social relations ("How have your physical health or emotional problems prevented you from communicating with family, friends, neighbours or other groups of people in the last 4 weeks?"); emotional state ("How often have you been very nervous in the last month?"); energy/ vitality ("How often have you felt the plenitude of life in the last month?"); pain ("How intense were the body aches in the last 4 weeks?"); and general health assessment ("It seems to me that I tend more to get sick than other people"). One response was used to calculate only one area. The numerical value for each area was from 0 to 100 (100 points indicated the best rating).

Previous reports indicate that the instrument has good internal consistency reliability (alpha $=$ .83 to .95 ) in the general population (Tanabe et al., 2010; Ware et al., 2008).

Statistical analysis. The data was analysed using SPSS version 22 statistics package. The data were described using the mean $(x)$ and standard deviation $( \pm S D)$. The Kolmogorov-Smirnov test was used to evaluate data normality and nonparametric Mann Whitney $U$-test was used to assess differences between two independent groups of competitive and recreational athletes; male and female athletes. Statistical significance was set at $p<.05$.

\section{RESULTS}

The first table presents respondents' evaluation of HRQL. The highest scores are seen on the scales of physical activity ( 96.28 points) and social relations (83.65 points). The lowest scores are observed on the scales related to activity limitation due to emotional (20.18 points) and physical (13.99 points) difficulties.

The second table presents the scores on scale evaluation of the competitive and recreational athletes' HRQL. We see that statistically significant differences were found in the evaluation of the quality of life in the following areas: social function, pain, and activity limitation due to emotional disorders. It was found that competitive athletes limited their activities more than recreational athletes due to emotional difficulties $(U=1165$, $p=.05)$ and experienced more pain $(U=1036$, $p=.01)$. It was also found that recreational athletes valued their social relations more favourably than competitive ones $(U=1066, p=.02)$.

The third table presents the results of the evaluation of HRQL by gender. Statistically significant differences between men's and women's life quality in individual areas were obtained by evaluating emotional status, and men rated it better than women $(U=1165, p=.05)$. Men also valued their social relations better $(U=992.5, p=.00)$ and 
Table 1. Evaluation of HRQL in participants

\begin{tabular}{|l|c|c|}
\hline \multicolumn{1}{|c|}{ Areas } & Mean $(\boldsymbol{n}=\mathbf{1 0 9})$ & Standard deviation \\
\hline Overall health assessment & 49.54 & \pm 10.42 \\
\hline Physical activity & 96.28 & \pm 5.66 \\
\hline Emotional status & 66.82 & \pm 16.44 \\
\hline Vitality & 62.93 & \pm 15.29 \\
\hline Social relations & 83.65 & \pm 16.57 \\
\hline Pain & 23.34 & \pm 16.69 \\
\hline Activity limitation due to emotional difficulties & 20.18 & \pm 31.43 \\
\hline Activity limitation due to physical difficulties & 13.99 & \pm 25.32 \\
\hline
\end{tabular}

Table 2. Evaluation of HRQL in competitive and recreational athletes

\begin{tabular}{|c|c|c|c|c|}
\hline Areas & $\begin{array}{c}\text { Recreational } \\
\text { athletes } \\
n=65\end{array}$ & $\begin{array}{c}\text { Competitive } \\
\text { athletes } \\
n=44\end{array}$ & \multirow[t]{2}{*}{$\boldsymbol{U}$} & \multirow[t]{2}{*}{$p$} \\
\hline & \multicolumn{2}{|c|}{ Normed Mean } & & \\
\hline Overall health assessment & 52.45 & 58.77 & 1264 & .29 \\
\hline Physical activity & 56.95 & 52.13 & 1303 & .37 \\
\hline Emotional status & 58.03 & 50.52 & 1233 & .22 \\
\hline Vitality & 54.2 & 56.18 & 1378 & .74 \\
\hline Social relations & 60.60 & 46.73 & 1066 & .02 \\
\hline Pain & 48.95 & 63.94 & 1036 & .01 \\
\hline Activity limitation due to physical difficulties & 53.16 & 57.72 & 1310 & .36 \\
\hline Activity limitation due to emotional difficulties & 50.93 & 61.01 & 1165 & .05 \\
\hline
\end{tabular}

Table 3. Evaluation of HRQL of female and male

\begin{tabular}{|c|c|c|c|c|}
\hline Areas & $\begin{array}{c}\text { Women } \\
n=56\end{array}$ & $\begin{array}{c}\text { Men } \\
n=53\end{array}$ & \multirow[t]{2}{*}{$\boldsymbol{U}$} & \multirow[t]{2}{*}{$p$} \\
\hline & \multicolumn{2}{|c|}{ Normed Mean } & & \\
\hline Overall health assessment & 53.92 & 56.14 & 1423 & .71 \\
\hline Physical activity & 54.10 & 55.95 & 1433 & .72 \\
\hline Emotional status & 49.30 & 61.02 & 1165 & .05 \\
\hline Vitality & 50.68 & 59.57 & 1242 & .13 \\
\hline Social relations & 46.22 & 64.27 & 992.5 & .00 \\
\hline Pain & 56.71 & 53.19 & 1388 & .55 \\
\hline Activity limitation due to physical difficulties & 53.40 & 56.69 & 1394 & .50 \\
\hline Activity limitation due to emotional difficulties & 62.30 & 47.28 & 1075 & .00 \\
\hline
\end{tabular}

had fewer activity limitations due to emotional difficulties than women $(U=1075, p=.00)$.

The fourth table shows the results of the HRQL evaluation by gender and sports level. Statistically significant differences between the areas of HRQL for men and women in recreational sports were found concerning social connections and activity limitation due to emotional difficulties. Men evaluated their social relationships better than women $(U=250$, $p=.00)$ and had fewer activity limitations due to emotional difficulties than women $(U=335, p=.00)$. Analysis of HRQL of competitive athletes showed no statistically significant relationship between women and men groups. 
Table 4. Evaluation of HRQL in competitive and recreational male and female athletes

\begin{tabular}{|c|c|c|c|c|c|c|c|c|}
\hline \multirow{3}{*}{ Areas } & \multicolumn{2}{|c|}{ Recreational athletes } & \multirow{3}{*}{$U$} & \multirow{3}{*}{$p$} & \multicolumn{2}{|c|}{ Competitive athletes } & \multirow{3}{*}{$U$} & \multirow{3}{*}{$p$} \\
\hline & $\begin{array}{c}\text { Women } \\
n=30\end{array}$ & $\begin{array}{l}\text { Men } \\
n=35\end{array}$ & & & $\begin{array}{c}\text { Women } \\
n=26\end{array}$ & $\begin{array}{l}\text { Men } \\
n=18\end{array}$ & & \\
\hline & \multicolumn{2}{|c|}{ Normed Mean } & & & \multicolumn{2}{|c|}{ Normed Mean } & & \\
\hline Overall health assessment & 30.70 & 34.97 & 456 & .35 & 23.42 & 21.17 & 210 & .55 \\
\hline Physical activity & 33.78 & 32.33 & 501.5 & .71 & 21.10 & 24.53 & 197 & .33 \\
\hline Emotional state & 29.03 & 36.40 & 406 & .11 & 20.56 & 25.31 & 183 & .22 \\
\hline Vitality & 30.87 & 34.83 & 461 & .39 & 20.31 & 25.67 & 177 & .17 \\
\hline Social relations & 23.83 & 40.86 & 250 & .00 & 22.17 & 22.97 & 225 & .83 \\
\hline Pain & 32.48 & 33.44 & 509.5 & .83 & 23.63 & 20.86 & 204 & .46 \\
\hline Activity limitation due to physical difficulties & 30.68 & 34.99 & 455.5 & .24 & 22.58 & 22.39 & 232 & .95 \\
\hline Activity limitation due to emotional difficulties & 39.33 & 27.57 & 335 & .00 & 23.50 & 21.06 & 208 & .49 \\
\hline
\end{tabular}

\section{DISCUSSION}

The study found that athletes, both competitive and recreational, emphasized physical activity and social relations when assessing their quality of life. This is confirmed by research of other scientists, which states that athletes evaluating their own QL scored the highest social relations and physical health and level of independence, and the lowest psychological health/spirituality domain (Nemček, 2020). Ekblom-Bak et al. (2018) emphasize that people who did sports from childhood and attended workouts and physical education classes, developed a healthy lifestyle, improved their skills for active leisure and were in better health condition compared with those who were less active and attended physical education classes minimally.

No significant differences were found on five of the eight scales when comparing HRQL in competitive and recreational athletes. The results of the study presented by Nemček, Kraček and Peráčková (2017) also did not determine significant differences in QL domains between elite/competitive athletes and recreational athletes. Interestingly, those athletes both competitive and recreational generally rated their health as average and no differences were found between those groups. This is in contrast to Correia et al. (2017) for the results of the study, which found that competitive athletes were characterized by high physical health satisfaction that could be explained by the fact that athletes trained daily, were monitored by coaches and physical training professionals, had qualified medical and psychological assistance in appropriate teams, and had a balanced diet.

The findings show that competitive athletes restrict theiractivities more than recreational athletes due to emotional difficulties, and experience more pain. Scientists (Rice et al., 2016) determined that competitive athletes were more likely to experience psychological disorders due to factors such as stress, pre-competition pressure to perform as well as possible, higher risk of injury, high publicity and media attention that recreational athletes did not face. Our study found that competitive athletes rated their social relations worse than recreational athletes. Analysing the results of other research, it can be seen that competitive athletes spend most of their time in training and preparing for competitions, and this way they lose lots of time which could have been allocated for communication with family and friends (Ohlert \& Ott, 2017), and there is also no time left for entertainment and leisure (Ho, 2018). With fewer social relations, competitive athletes run the risk of experiencing emotional hardships, while the younger athletes do not develop social skills that are so important for good psychological health (Ohlert \& Ott, 2017).

Another task of the study was to determinate the HRQL differences between females and males. It was found that HRQL differed statistically significantly between men and women in only three indicators (out of eight). Men valued their emotional state better and had fewer activity limitations due to 
emotional difficulties. This is consistent with data from other studies, where male athletes were found to be significantly more satisfied with their leisure time and sport than women, while male athletes expressed the greatest dissatisfaction with their psychological health and spirituality (Nemček, 2020). Interpreting these data, the researchers report that women have higher levels of hormonal fluctuations and greater emotional vulnerability, which is associated with reproductive functions and genetically determined higher emotional sensitivity (Zagni, Simoni, \& Colombo, 2016). Sexual harassment and abuse of women in sport are also mentioned more often, and this is explained by the feminist theory that emphasises cultural dimensions: structural power, gender inequality, patriarchy, and socialization of gender roles (Fasting, Brackenridge \& Knorre, 2010; Johansson $\&$ Lundqvist, 2017). All of this can lead to negative and depressive thoughts (Picco, Subramaniam, Abdin, Vaingankar, \& Chong, 2017).

In our study, we found that men valued their social relations better than women. Unver et al. (2015) also found that female athletes had lower social scores than men, but recent studies did not show any differences in social relations between male and female athletes (Nemček, 2020).
Some differences in HRQL in men and women of recreational sports were also found: men evaluated their social relationships better than women and had fewer activity limitations due to emotional difficulties than women. Analysis of HRQL of competitive athletes showed no statistically significant relationship between women and men groups.

\section{CONCLUSION}

In conclusion, it can be stated that athletes best value areas of physical activity and social relations. The findings show that competitive athletes more than recreational ones limit their activities due to emotional difficulties, and experience more pain. Meanwhile, recreational athletes rate their social relations more favourably than competitive athletes.

Male athletes value their social relations and emotional state better than female athletes do. Men also have fewer activity limitations due to emotional difficulties than women.

Based on the results of the study, more attention should be paid to the competitive athletes, especially females, their mental health, helping them to maintain a good emotional state (supporting and encouraging them) and psychological recovery after strenuous training periods and competitions, using various methods of relaxation and self-regulation.

\section{REFERENCES}

Anshel, M.H., Sutarso, T., \& Jubenville, C. (2009). Racial and gender differences on sources of acute stress and coping style among competitive athletes. The Journal of Social Psychology, 149(2),159-178. doi: http://dx.doi. org/10.3200/SOCP.149.2.159-178

Babic, V., Bjelic, G., \& Bosnar, K. (2019). Life wellbeing and reasons for the termination of sport careers among Croatian elite athletes. Sport Mont, 17(3), 21-25. doi: http://dx.doi.org/10.26773/smj.191008

Batz, C., \& Tay, L. (2018). Gender Differences in Subjective Well-Being. Salt Lake: Handbook of wellbeing. Salt Lake City, UT: DEF Publishers.

Beery, A. K., \& Zucker, I. (2011). Sex bias in neuroscience and biomedical research. Neuroscience and Biobehavioral Reviews, 35(3), 565-572. doi: http:// dx.doi.org/10.1016/j.neubiorev.2010.07.002

Bompa, T.O., \& Haff, G.G. (2018). Periodization: theory and methodology of training. Human Kinetics.

Brazier, J., Papaioannou, D., Connell, J., \& Mukuria, C. (2014). A systematic review, psychometric analysis and qualitative assessment of generic preference-based measures of health in mental health populations and the estimation of mapping functions from widely used specific measures. Health Technology Assessment, 18(34), 1-188. doi: https://doi.org/10.3310/hta18340

Cakir, G., \& Kalkavan, A. (2020). The relationship between healthy lifestyle behaviors and quality of life: An analysis on university students who are engaged in sports and who are not. European Journal of Physical Education and Sport Science, 6(5), 17-34. doi: https:// doi.org/10.5281/zenodo.3885875

Carlquist, E., Ulleberg, P., Delle Fave, A., Nafstad, E. H., \& Blakar, M. R. (2017). Everyday understandings of happiness, good life, and satisfaction: Three different facets of well-being. Applied Research in Quality of Life, 12(2), 481-505. doi: https://doi.org/10.1007/S11482016-9472-9

Correia, R.F., Ribeiro, A.N., Barbieri, J.F., Brazil, D., Motta, L., Castano, L.A.A, \& Salve, M.G.C. (2017). Quality of life levels in Brazilian elite female college volleyball players. International Journal of Sports Science, 7(1), 6-9. doi: https://doi.org/10.2478/ afepuc-2020-0009

de Oliveira, L. D., Edila, C. S., Rodrigues, S. A., Fett, A. C., \& Piva, B. A. (2019). The effects of physical activity on anxiety, depression, and quality of life in elderly people living in the community. Trends in 
Psychiatry and Psychotherapy, 41(1), 36-42. doi: https:// doi.org/10.1590/2237-6089-2017-0129

Demirci, I., \& Ekşi, H. (2018). Keep calm and be happy: A mixed method study from character strengths to well-being. Educational Sciences: Theory \& Practice, 18(2), 279-330. doi: http://dx.doi.org/10.12738/ estp.2018.2.0799

Ekblom-Bak, E., Ekblom, Ö., Andersson, G., Wallin, P., \& Ekblom, B. (2018). Physical education and leisuretime physical activity in youth are both important for adulthood activity, physical performance, and health. Journal of Physical Activity and Health, 15, 661-670. doi: https://doi.org/10.1136/bjsports-2012-092038

Fasting, K., Brackenridge, C., \& Knorre, N. (2010). Performance level and sexual harassment prevalence among female athletes in the Czech Republic. Women in Sport and Physical Activity Journal, 19, 26-32. doi: http://dx.doi.org/10.1123/wspaj.19.1.26

Filbay, S., Pandya, T., Thomas, B., McKay, C., Adams, J., \& Arden, N. (2019). Quality of life and life satisfaction in former athletes: A systematic review and meta-analysis. Sports Medicine, 49(11), 1723-1738. doi: https://doi. org/10.1007/s40279-019-01163-0

Goraczko, A., Zurek, G., Lachowicz, M., Kujawa, K., Blach, W., \& Zurek, A. (2020). Quality of Life after spinal cord injury: A multiple case study examination of elite athletes. International Journal of Environmental Research and Public Health, 17(20), 7437. doi: https:// doi.org/10.3390/ijerph17207437

Gulliver, A., Griffiths, M. K., Mackinnon, A., Batterham, J. P., \& Stanimirovic, R. (2016). The mental health of Australian elite athletes: A narrative systematic review. Sports Medicine, 46(9), 1333-1353.

Ho, T.S. (2018). An exploration of relationship among leisure involvement, leisure benefits, quality of life, and training effects of collegiate athletes. The International Journal of Organizational Innovation, 10(4), 327-344.

Johansson, S., \& Lundqvist, C. (2017). Sexual harassment and abuse in coach-athlete relationships in Sweden. European Journal for Sport and Society, 14(2), 117-137. doi: https://doi.org/10.1080/16138171.2017.13 $\underline{18106}$

Kalman, K., \& Hantiu, I. (2017). Effects of physical activity on the quality of life among adult women. Timişoara Physical Education and Rehabilitation Journal, 10(19), 109-114.

Koolhaas, M. C., Dhana, K., van Rooij, A. J., Schoufour, D. J., Hofman, A., \& Franco, H.O. (2018). Physical activity types and health-related quality of life among middle-aged and elderly adults: The Rotterdam study. The Journal of Nutrition, Health \& Aging, 22, 246253. doi: https://doi.org/10.1007/s12603-017-0902-7

Lorcan, D. C., \& Allen, J. (2018). Examining the relationships among the coaching climate, life skills development and well-being in sport. International Journal of Sports Science \& Coaching, 13(6), 815-827. doi: https://doi.org/10.1177\%2F1747954118787949

Nemček, D., Kraček, S., \& Peračkova, J. (2017). Rosenberg Self-Esteem Scale analyses among elite and competitive athletes, recreational athletes and inactive individuals. Journal of Physical Education and Sport, 17(5), 2305-2310. doi: http://dx.doi.org/10.7752/ jpes.2017.s5249

Nemček, J. (2020). Gender differences in subjective quality of life of elite and competitive sports games players. Acta Facultatis Educationis Physicae Universitatis Comeniana, 60(1), 105-112. doi: https:// doi.org/10.2478/afepuc-2020-0009

Ohlert, J., \& Ott, I. (2017). Developmental tasks and well-being in adolescent elite athletes in comparison with recreational/non-athletes. European Journal of Sport Science, 17(10), 1343-1349. doi: https://doi.org/10 $.1080 / 17461391.2017 .1365935$

Pacesova, P., Smela, P., \& Antala, B. (2019). Male's level of personal well-being and anxiety trait regarding a sport activity level. Sport Mont, 17(2), 59-62. doi: https://doi. org/10.26773/smj.190610

Päivärinne, V., Kautiainen, H., Heinonen, A., \& Kiviranta, I. (2018). Relations between subdomains of physical activity, sedentary lifestyle, and quality of life in young adult men. Scandinavian Journal of Medicine \& Science in Sports, 28, 1389-1396. doi: http://dx.doi. org $/ 10.1111 /$ sms.13003

Petterson, H., \& Olson, L.B. (2017). Effects of mindfulness-based interventions in high school and college athletes for reducing stress and injury, and improving quality of life. Journal of Sport Rehabilitation, 26, 578-587. doi: https://doi.org/10.1123/jsr.2016-0047

Picco, L., Subramaniam, M., Abdin, E., Vaingankar, A. J., \& Chong, A. S. (2017). Gender differences in major depressive disorder: findings from the Singapore Mental Health Study. Singapore Medical Journal, 58(11), 649655. doi: https://doi.org/10.11622/smedj.2016144

Rice, M.S., Purcell, R., De Silva, S., Mawren, D., McGorry, D.P., \& Parker, G.A. (2016). The mental health of elite athletes: A narrative systematic review. Sports Medicine, 46(9), 1333-1353. doi: http://doi.org/10.1007/ s40279-016-0492-2

Schinke, R. J., Stambulova, N. B., Gangyan, S., \& Moore, Z. (2017). International society of sport psychology position stand: Athletes' mental health, performance, and development. International Journal of Sport and Exercise Psychology, 16(6), 622-639. doi: http://dx.doi.org/10.1080/1612197X.2017.1295557

Snedden, T. R., Scerpella, J., Kliethermes, S. A., Norman, R. S., Blyholder, L., Sanfilippo, J., McGuine, T.A., \& Heiderscheit, B. (2019). Sport and physical activity level impacts health-related quality of life among collegiate students. American Journal of Health Promotion, 33(5), 675-682. doi: https://doi.org/10.1177/0890117118817715 Stambulova, N. B. (1994). Developmental sports career investigations in Russia: A post-perestroika analysis. The Sport Psychologist, 8, 221-237. doi: https://doi. org/10.1123/tsp.8.3.221

Staniūte, M. (2007). Su sveikata susijusios gyvenimo kokybès vertinimas naudojant SF-36 klausimyną. Biologine psichiatrija ir psichofarmakologija, 9(1), 2225. 
Tanabe, T., Snyder, A.R., Curtis Bay, R., \& Valovich McLeod, T. C. (2010). Representative values of healthrelated quality of life among female and male adolescent athletes and the impact of gender. Athletic Training \& Sports Health Care, 2(3), 106-112.

Unver, S., Atan, T., Cavusoglu, G., Erim, V., \& Yamak, B. (2015). A comparison of levels of quality of life, depression and loneliness among athletes with different levels of training. Educational Research and Reviews, 10(2), 130-134.
Ware, J. E., Kosinski, M., Bjorner, J. B., TurnerBowker, D. M., Gandek, B., \& Maruish, M.E. (2008). User's Manual for the SF-36v2 Health Survey. 2nd ed. Lincoln, RI: QualityMetric Incorporated.

WHO (2012). WHOQOL: Measuring Quality of Life. Retrieved from https://www.who.int/tools/whoqol

Zagni, E., Simoni, L., \& Colombo, D. (2016). Sex and Gender Differences in Central Nervous System-Related Disorders. Neuroscience Journal, 30, 1-13. doi: https:// doi.org/10.1155/2016/2827090 